\title{
Adsorption isotherm studies of $\mathrm{Cu}$ (II) and $\mathrm{Co}$ (II) in high concentration aqueous solutions on photocatalytically modified diatomaceous ceramic adsorbents
}

\author{
E. Ajenifuja ${ }^{1}$ J. A. Ajao ${ }^{1}$ E. O. B. Ajayi ${ }^{2}$
}

Received: 10 June 2016/Accepted: 3 January 2017/Published online: 16 January 2017

(C) The Author(s) 2017. This article is published with open access at Springerlink.com

\begin{abstract}
Photocatalytically modified ceramic adsorbents were synthesized for the removal of high concentration $\mathrm{Cu}$ (II) and Co (II) ions from their aqueous solutions. The raw material, diatomaceous aluminosilicate mineral was modified using silver and anatase titanium oxide nanoparticles. Batch adsorption experiment was carried out on the targeted metal ions and the results were analyzed by the Langmuir and Freundlich equation at different concentrations (100-1000 $\mathrm{mg} / \mathrm{l})$ and the characteristic parameters for each adsorption isotherm were determined. As-received raw materials do not exhibit any sorption capacity for high concentration $\mathrm{Cu}^{2+}$ and $\mathrm{Co}^{2+}$ adsorbates. However, the adsorption isotherms for modified diatomaceous ceramic adsorbents could be fitted well by the Langmuir model for both $\mathrm{Cu}^{2+}$ and $\mathrm{Co}^{2+}$ with correlation coefficient $(R)$ of up to 0.99953 . The highest and lowest monolayer coverage $\left(q_{\max }\right)$ were 121.803 and $31.289 \mathrm{mg} / \mathrm{g}$ for $\mathrm{Cu}^{2+}$ and $\mathrm{Co}^{2+}$, respectively. The separation factor $\left(R_{\mathrm{L}}\right)$ in the experiment was less than one $(<1)$, indicating that the adsorption of metal ions on the $\mathrm{Ag}-\mathrm{TiO}_{2}$-modified ceramic adsorbent is favorable. The highest adsorption capacity $\left(K_{\mathrm{f}}\right)$ and intensity $(n)$ constants obtained from Freundlich model are $38.832\left(\mathrm{Cu}^{2+}\right.$ on ZEO-T $)$ and $5.801\left(\mathrm{Co}^{2+}\right.$ on STOX-Z).
\end{abstract}

Keywords Diatomaceous ceramic Adsorption capacity · Freundlich $\cdot$ Spectrophotometry $\cdot$ Langmuir $\cdot$ Separation factor

E. Ajenifuja

eajenifuja@gmail.com; eajenifuja@cerd.gov.ng

1 Center for Energy Research and Development, Obafemi Awolowo University, Ile-Ife, Nigeria

2 Department of Physics, Obafemi Awolowo University, Ile-Ife, Nigeria

\section{Introduction}

Metal ions are used in various industries due to their technological importance: metal processing, electroplating, electronics and a wide range of chemical processing industries. Hence, treatment of contaminated waste should be considered a priority, before being discharged into the environment (Rio and Patrick 2012). Pollution of ground and surface waters with toxic metals ions leachate from industries and urban dumpsites is a major problem since most heavy metals like copper, cobalt, cadmium, chromium, lead, etc. are not biodegradable and hence they tend to accumulate in living organisms with an enduring toxic and carcinogenic effect on the body (Pfeiffer 1997; Desai and Kaler 2008; Araya et al. 2005; Johnson et al. 1992; Moradi et al. 2012; Kim et al. 2006; Mendy et al. 2012). Water pollution and its remediation are principal health issues, and various procedures have been proposed including chemical precipitation, membrane filtration, ion exchange, coagulation, electrocoagulation, and adsorption. In the meantime, adsorption is considered a reliable process that can be used to remediate a mixture of contaminants with low concentrations (Chermisinoff and Ellerbusch 1978). Naturally occurring and synthesized materials have been employed as adsorbent (Mittal et al. 2015a, b; Naushad et al. 2014; Mittal and Kurup 2006). Synthetic materials appear to be particularly competitive and effective for the removal of heavy metals at trace level (Shawabkeh 1998). Besides, the use of synthetic adsorbents is considered inapt for developing countries because of its high manufacturing cost. Recently, attempts have been made to increase the sorption capacity of natural adsorbents towards heavy metals by chemical modification of their surface (Knoerr et al. 2013; Şan et al. 2009; Zhu et al. 2012; Liu et al. 2013; Han et al. 2006, 2009; Jeon et al. 
2009; Zou et al. 2009; Choi et al. 2012). The common and highest concentration for heavy metal adsorption in aqueous solution in most recent investigations has been between 200 and $300 \mathrm{mg} / \mathrm{l}$. Nonetheless, the concentration is often higher in situations involving the release of heavy metal to the environment from manufacturing plants (Apostoli et al. 2012). Hence, increasing the capability of adsorbents to remove heavy metals at high concentrations (Ajenifuja et al. 2016) is emphatically significant for the survival of organisms in the environment. With the current trend, if high concentrations of toxic pollution occur in emergency as effluents from factories or mining sites, trace and low concentration adsorbents may not be suitable to save the situation. There are needs for adsorbents for high concentrations pollutants $(100-1000 \mathrm{mg} / \mathrm{l})$. The foregoing presents necessity for continual studies and investigations on the preparation of an efficient, portable and affordable water remediation materials and gadgets for domestic applications.

With the additional value of being inexpensive and readily available, natural clay aluminosilicate possesses unique combination of physical and chemical properties which makes it suitable for a wide range of industrial applications (Wu et al. 2005; De Castro Dantas et al. 2001; Irani et al. 2011; Khan et al. 2015; Jiang et al. 2010; Bhattacharyya and Gupta 2006, 2008a, b; Gupta and Bhattacharyya 2008; Karaoğlu et al. 2010). However, it is important to increase its adsorptive capacity of natural adsorbent to meet wider range of challenges; this is usually achieved by increasing the number of chemically active sites or enlarging its surface area. The removal and addition of cations using aluminosilicates are dependent on ion exchange and adsorption mechanisms. Most recent works on the use of modified diatomaceous aluminosilicate as adsorbents are based on the removal of toxic metals from aqueous solutions at relatively low concentrations which may not always be the case in real situations (Linghu and Cui 2014; Knoerr et al. 2013; Zhu et al. 2012; Liu et al. 2013; Irani et al. 2011; Danil de Namor et al. 2012; Yusan et al. 2012; Sheng et al. 2008, 2012; Sprynskyy et al. 2010; Pookmanee et al. 2011). Also natural diatomites are contaminated with impurities, which impact negatively on their removal of heavy ions (Zhu et al. 2012). Hence, activation of the diatomite surface becomes necessary for removal process optimization. Photocatalytic nature of $\mathrm{TiO}_{2}$ has been utilized in the environmental remediation studies (Hanaor et al. 2011; Hanaor and Sorrell 2014; Yang et al. 2012; Lasek et al. 2012; Kujawa et al. 2013; Kamegawa et al. 2013). Wu et al. (2009) reported visible light-induced photocatalytic inactivation of bacteria with nitrogen-doped $\mathrm{TiO}_{2}$.

Toxic metal contamination is a global challenge, and an inexpensive and simple solution is required. Utilizing pure photocatalysts (titanium oxide) may not be feasible due to cost and availability for other applications. Modification of raw diatomite with photocatalyst $\mathrm{Ag}-\mathrm{TiO}_{2}$ enhances its removal efficiency by photo-degradation of the pollutant even at high concentrations as demonstrated. In this work, $\mathrm{TiO}_{2}$ was doped with $\mathrm{Ag}$ nanoparticles in order to extend the photo-activation of the catalyst to the visible range, which will make the use of the ceramic adsorbent to be possible everywhere. This study investigated the use of photocatalytically modified local diatomite as adsorbents for the removal of $\mathrm{Co}$ (II) and $\mathrm{Cu}$ (II) ions from high concentration aqueous solutions.

\section{Materials and methods}

\section{Raw materials}

The abundantly available diatomaceous aluminosilicate materials were sourced in northern Nigeria. Diatomaceous earth usually occurs in two types of geological environments, marine and lake. This raw material sample used in this work was obtained in North-East Nigeria, which is close to the Lake Chad basin; therefore, it was originated most probably in the lacustrine environment. The obtained dried sample is a loosely cemented porous and lightweight rock of sedimentary origin, mainly formed from skeleton of diatomea. The modifying materials are anatase $\mathrm{TiO}_{2}$ nanoparticles and $\mathrm{AgNO}_{3}$ salt, which was used as the silver ion source. Sodium carbonate $\left(99.0 \%, \mathrm{Na}_{2} \mathrm{CO}_{3}\right)$ was used to reduce the silver ions.

\section{Diatomaceous powder preparations (ZEO)}

The raw material was pulverized and the fine powder obtained was mixed with distilled water in a beaker to form a colloid. The colloidal solution was agitated and left for a few minutes for heavy unwanted particles and other impurities to settle at the base of the beaker; thereupon the top suspension was separated into another beaker, and the process was repeated until a homogeneous gray gelatinous separate was obtained and then centrifuged. The collected diatomaceous gel was transferred into an oven for drying for $18 \mathrm{~h}$ at $100{ }^{\circ} \mathrm{C}$; and a soft white lightweight cake was formed. To enhance the surface properties of the aluminosilicate material, activation was carried out on the welldried diatomaceous powder using $30 \%$ dilute $\mathrm{HNO}_{3}$. The acid treatment was intended for dissolution of some amorphous materials that might block the natural pores of the raw materials and give way to the modifying photocatalyst. Silver nanoparticles were loaded into the modifying anatase $\mathrm{TiO}_{2}$ nanopowder to give $\mathrm{Ag}-\mathrm{TiO}_{2}$ (STOX); this was intended to extend the photo-activity of the ceramic powder well into the visible region. Silver nitrate 
$\left(\mathrm{AgNO}_{3}\right)$ was used as the silver ions source. For the preparation, $10 \mathrm{~g}$ of anatase $\mathrm{TiO}_{2}$ powder was placed into a $500 \mathrm{ml}$ beaker with $100 \mathrm{ml}$ ethanol as the dispersion medium. Then, $0.1 \mathrm{M}$ solution of $\mathrm{AgNO}_{3}$ and $1 \%(\mathrm{w} / \mathrm{v})$ solution of sodium carbonate (reducing agent) were prepared separately. Hence, $4.6 \mathrm{ml}$ of the prepared silver nitrate solution and $5 \mathrm{ml}$ of sodium carbonate were added into the beaker containing the dispersed $\mathrm{TiO}_{2}$. The mixture was stirred vigorously for $2 \mathrm{~h}$ with magnetic stirrer to form a slurry solution and afterwards the solid material (Ag$\mathrm{TiO}_{2}$ ) was collected by centrifugation. The collected modified $\mathrm{TiO}_{2}$ nanoparticle was dried in the furnace at $100{ }^{\circ} \mathrm{C}$ for about $24 \mathrm{~h}$; thereafter, the powder was calcined at $400{ }^{\circ} \mathrm{C}$ for $12 \mathrm{~h}$ to remove leftover organics and also for thermal diffusion of the material.

\section{Modified diatomaceous ceramic adsorbents (ZEO-T and STOX-Z)}

$\mathrm{Ag}-\mathrm{TiO}_{2}$-modified diatomaceous ceramic adsorbents were prepared using two procedural routes. For the preparation of adsorbent ZEO-T, the prepared $\mathrm{Ag}-\mathrm{TiO}_{2}$ powder (STOX) was ring milled with the $\mathrm{HNO}_{3}$-treated diatomaceous aluminosilicate powder (ZEO) in other to achieve mechano-chemical interactions and uniform distribution of constituents in the ceramic composite. This was followed by solid-state fusion; the milled mixture was subjected to high temperature-pressure treatment at $800{ }^{\circ} \mathrm{C}$. To prepare ceramic adsorbent STOX-Z, dispersion of modified Agmodified $\mathrm{TiO}_{2}$ was prepared as earlier described in Sect. 2.2. Then, depending on the quantity proposed, $25 \mathrm{~g}$ of $\mathrm{HNO}_{3}$-treated diatomaceous aluminosilicate powder was added slowly into the continuously stirred $\mathrm{Ag}-\mathrm{TiO}_{2}$ colloidal solution (see Fig. 1). The slurry solution formed was stirred and mildly heated simultaneously for $2 \mathrm{~h}$ on the hot plate. The final modified diatomaceous aluminosilicate powder adsorbent STOX-Z was recovered from the slurry solution via centrifugation as shown in Fig. 1. Conspicuous visible light-induced color change was observed for the STOX-Z particles when exposed to daylight due to photoreaction. The constituents of the ceramic powder are highlighted in Table 1. The micrographs of the prepared diatomaceous clay adsorbents ZEO-T, STOX-Z and STOX are shown in Fig. 2a, b and c, respectively. In the SEM images, $\mathrm{Ag}-\mathrm{TiO}_{2}$ nanoparticles are shown to be well distributed and coalesced around the surface and micropore structure of the diatomaceous aluminosilicate.

\section{Adsorption experiments}

The stock solutions of $\mathrm{Cu}$ (II) and $\mathrm{Co}$ (II) were prepared from their commercial salts (sulphates and nitrates, respectively) and the solutions were normalized titrimetrically. Other required concentrations were made with appropriate dilutions from the stock. Batch adsorption tests were carried out in $50 \mathrm{ml}$ Pyrex beakers. For each adsorption test, $0.125 \mathrm{~g}$ of raw and modified ceramic powder adsorbents was added to $20 \mathrm{ml}$ of aqueous solutions at room temperature. The ion-adsorbent mixtures were shaken for $2 \mathrm{~min}$ for even distribution of the adsorbent particles in the solution and then kept for $12 \mathrm{~h}$ for saturation. The high concentration aqueous solutions resembled effluents obtainable in real life contamination scenarios. The aqueous phase was separated from the ceramic adsorbent by centrifugation after $12 \mathrm{~h}$ and the new equilibrium concentrations of the cation in final solution were monitored using UV-visible spectrophotometer (Thermoscientific: Helio Omega). The proper absorbance-concentration calibrations based on BeerLambert's law were carried out at every stage of the spectrophotometric measurement to determine the equilibrium concentrations. The effect of initial concentrations of the aqueous solutions of $\mathrm{Cu}$ and $\mathrm{Co}$ on the adsorption capacity of the ceramic adsorbents was also determined from the solutions with concentrations ranging from 100 to $1000 \mathrm{mg} / \mathrm{l}$. The amount of adsorbed $\mathrm{Cu}^{2+}$ and $\mathrm{Co}^{2+}$ (mg ion/g ceramic adsorbent) was calculated from the decrease in concentration in the media. The initial and equilibrium concentrations of the adsorbates were measured and compared to know the extent of the removal. The initial and final concentrations of the adsorbates are displayed in Table 2.

The adsorbed $\mathrm{Cu}^{2+}$ and $\mathrm{Co}^{2+}$ ions ( $\mathrm{mg}$ ions/g ceramic adsorbent) were determined basically by taking into account, the decrease in the concentrations of $\mathrm{Cu}$ and $\mathrm{Co}$ ions, the adsorption volume and the amount of ceramic adsorbent used for each process:

$q_{\mathrm{e}}=\left[\left(C_{\mathrm{i}}-C_{\mathrm{e}}\right) \times V\right] / m$,

where $q_{\mathrm{e}}$ is the amount of metal ions adsorbed onto unit mass of the clay $\left(\mathrm{mg} \mathrm{Cu}{ }^{2+}\right.$ or $\mathrm{Co}^{2+} / \mathrm{g}$ adsorbent) at equilibrium; $C_{\mathrm{i}}$ and $C_{\mathrm{e}}$ are the concentrations of the metal ions in the initial solutions and in the aqueous phase after treatment for certain adsorption time; $\mathrm{m}$ is the amount of the ceramic powder used $(\mathrm{g})$ and $V$ is the volume of the aqueous solution (liter).

\section{Results and discussion}

\section{Influence of concentrations of adsorbate}

The study of the influence of initial concentrations of the metal ions in the aqueous solutions was carried out and the upper limit of the adsorption capacities of the diatomaceous aluminosilicate adsorbents for $\mathrm{Cu}$ (II) and Co (II) 
Fig. $1 \mathrm{Ag}-\mathrm{TiO}_{2}$-modified diatomaceous aluminosilicate ceramic membrane preparation steps

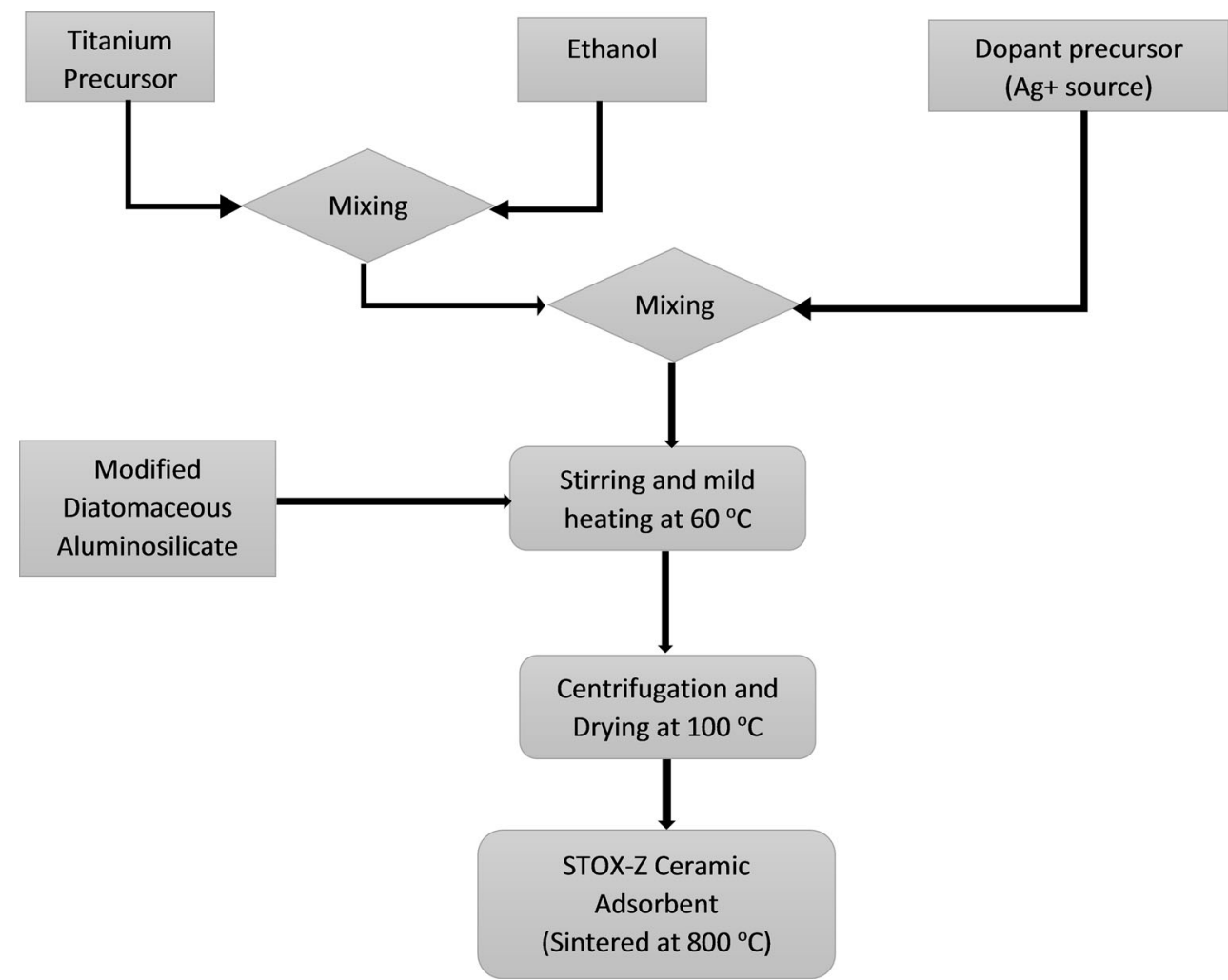

Table 1 Constituents of the ceramic membrane precursor materials

\begin{tabular}{|c|c|c|c|}
\hline \multirow[t]{2}{*}{ Sample } & \multicolumn{3}{|l|}{ Constituents } \\
\hline & Diatomaceous aluminosilicate & $\mathrm{Ag}-\mathrm{TiO}_{2}$ (thermal) & $\mathrm{Ag}-\mathrm{TiO}_{2}(\mathrm{Sol}-\mathrm{Gel})$ \\
\hline ZEO & $\sqrt{ }$ & - & - \\
\hline ZEO-T & $\sqrt{ }$ & $\sqrt{ }$ & - \\
\hline STOX-Z & $\sqrt{ }$ & - & $\sqrt{ }$ \\
\hline
\end{tabular}
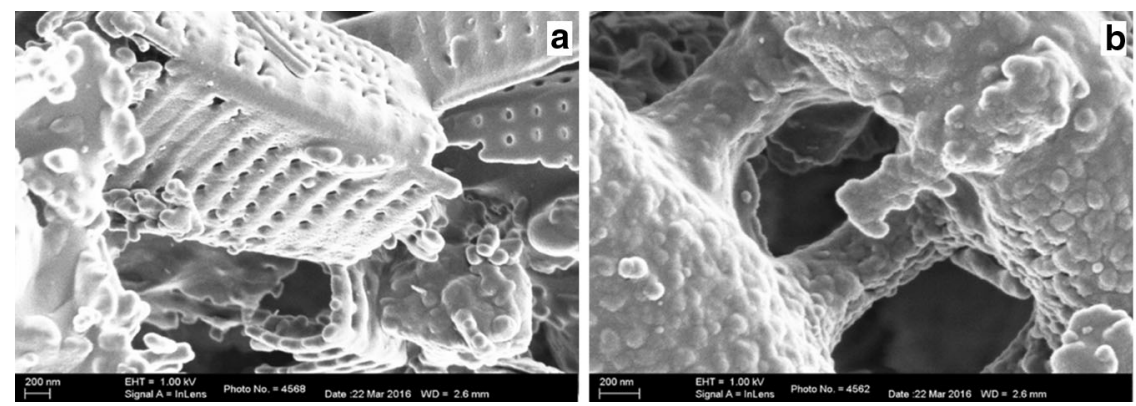

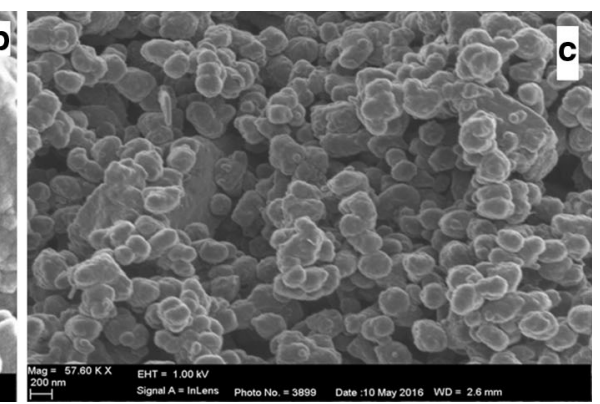

Fig. 2 SEM micrographs for diatomaceous ceramic adsorbents a ZEO-T b STOX-Z and c STOX

ions was determined. The characteristic behavior of the adsorbents with respect to the initial concentrations of the metal ions is shown in Figs. 3 and 4 for $\mathrm{Cu}$ (II) and Co (II), respectively. For $\mathrm{Co}^{2+}$ adsorption, sample ZEO-T exhibited a promising behaviour by attaining the highest
$\mathrm{Co}^{2+}$ removal capacity, all through the concentration range in term of quantity of cations absorbed in $\mathrm{mg} / \mathrm{g}$. Samples STOX-Z showed a different relationship in terms of their behavior with the highest $\mathrm{Co}^{2+}$ quantity adsorbed being about $30 \mathrm{mg} / \mathrm{g}$. It should be noted that though quantity 
Table 2 Initial and final concentrations of $\mathrm{Cu}^{2+}$ and $\mathrm{Co}^{2+}$ solutions determined using UV-visible spectrophotometer

\begin{tabular}{|c|c|c|c|c|}
\hline \multirow[t]{2}{*}{ Samples } & \multicolumn{2}{|l|}{ Copper } & \multicolumn{2}{|l|}{ Cobalt } \\
\hline & Initial (mg/l) & Final (mg/l) & Initial (mg/l) & Final (mg/l) \\
\hline \multirow[t]{3}{*}{ ZEO-T } & 200 & 5 & 200 & 12.5 \\
\hline & 500 & 10 & 500 & 150 \\
\hline & 1000 & 265 & 1000 & 550 \\
\hline \multirow[t]{3}{*}{ STOX-Z } & 200 & 10 & 200 & 75 \\
\hline & 500 & 65 & 500 & 312.5 \\
\hline & 1000 & 445 & 1000 & 812.5 \\
\hline
\end{tabular}

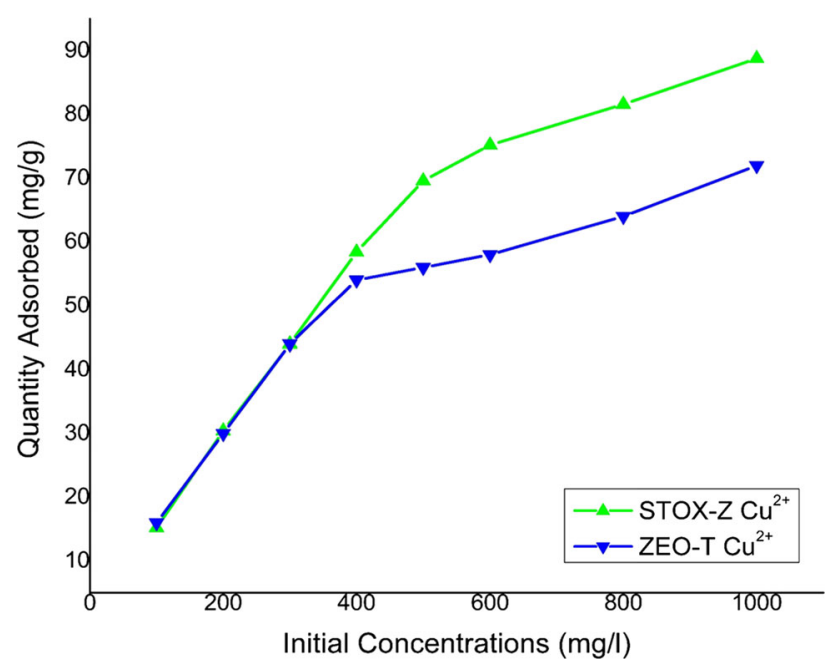

Fig. 3 Effect of initial adsorbate concentrations on the adsorption capacities of $\mathrm{Cu}^{2+}$

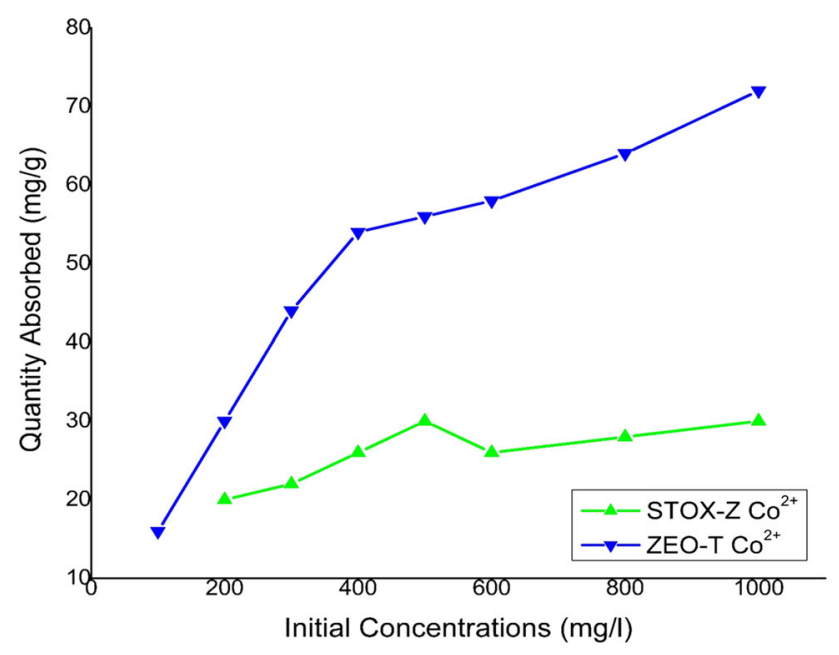

Fig. 4 Effect of initial adsorbate concentrations on the adsorption capacities of $\mathrm{Co}^{2+}$

adsorbed rose with the concentrations, however, considering the removal in percentage term, with the rise in the concentration, the percentage uptake by the adsorbents reduced steadily. Meanwhile, the adsorption capacities of the adsorbents for $\mathrm{Cu}^{2+}$ followed nearly almost the same pattern but with STOX-Z adsorbing the highest quantity of $\mathrm{Cu}^{2+}$ especially at higher adsorbate concentrations. Nonetheless, both adsorbents ZEO-T and STOX-Z share the same adsorption capacity trend at lower solution concentrations up to about $400 \mathrm{mg} / \mathrm{l}$.

\section{$\mathrm{Cu}^{2+}$ and $\mathrm{Co}^{2+}$ adsorption isotherm}

To comprehend the removal mechanism of $\mathrm{Cu}$ (II) and $\mathrm{Co}$ (II) ions by $\mathrm{Ag}-\mathrm{TiO}_{2}$-modified diatomaceous ceramic adsorbent, the study of adsorption mechanisms becomes important. It is understood both in theory and experiments (Lippens and De Boer 1965; Reed and Matsumoto 1993; Malik 2004) that ions and molecules both in liquid and gaseous forms can adsorb on the surface of certain adsorbent. Therefore, the likeliest mechanism by which ceramic adsorbents remove metals ions from solutions are by forming monolayers on the surface of the porous and nonporous adsorbent particles. In this work, adsorption of $\mathrm{Cu}$ (II) and Co (II) in the aqueous solutions is described through isotherms, that is, functions which connect the amount of adsorbate on the adsorbent. Distribution of metal ions between the liquid phase and the solid phase can be described by several isotherm models such as Langmuir and Freundlich. In the case of Langmuir isotherm model, it is assumed that monolayer adsorption onto a surface contains a finite number of adsorption sites of uniform strategies with no transmigration of adsorbate in the plane surface, i.e., once a site is filled, no further sorption can take place at that site (Hameed et al. 2007). This indicates that the surface reaches a saturation point where the maximum adsorption of the surface will be achieved. The adsorption of $\mathrm{Cu}$ (II) and Co (II) ions in solutions was recorded in the concentration range from 100 to $1000 \mathrm{mg} / \mathrm{l}$ mimicking a high concentration contamination conditions. The profiles obtained from the studies of the concentrations at room temperature were used to obtained Langmuir and 
Table 3 Langmuir and Freundlich parameters for the ceramic adsorbent materials

\begin{tabular}{|c|c|c|c|c|c|c|c|c|}
\hline \multirow[t]{3}{*}{ Samples } & \multicolumn{8}{|c|}{ Isotherm models } \\
\hline & \multirow[t]{2}{*}{ Metal ion } & \multicolumn{4}{|c|}{ Langmuir parameters } & \multicolumn{3}{|c|}{ Freundlich parameters } \\
\hline & & $q_{\max }(\mathrm{mg} / \mathrm{g})$ & $b(\mathrm{mg} / \mathrm{l})$ & $R_{\mathrm{L}}$ & $R$ & $n$ & $K_{\mathrm{f}}$ & $R$ \\
\hline \multirow[t]{2}{*}{ STOX-Z } & $\mathrm{Cu}$ & 91.912 & 0.041 & $0.024-0.196$ & 0.99915 & 2.813 & 12.558 & 0.92723 \\
\hline & $\mathrm{Co}$ & 31.289 & 0.021 & $0.045-0.319$ & 0.99702 & 5.801 & 9.744 & 0.89631 \\
\hline \multirow[t]{2}{*}{ ZEO-T } & $\mathrm{Cu}$ & 121.803 & 0.108 & $0.009-0.084$ & 0.99953 & 4.594 & 38.832 & 0.90779 \\
\hline & $\mathrm{Co}$ & 70.721 & 0.045 & $0.022-0.180$ & 0.99455 & 5.580 & 22.721 & 0.98324 \\
\hline
\end{tabular}
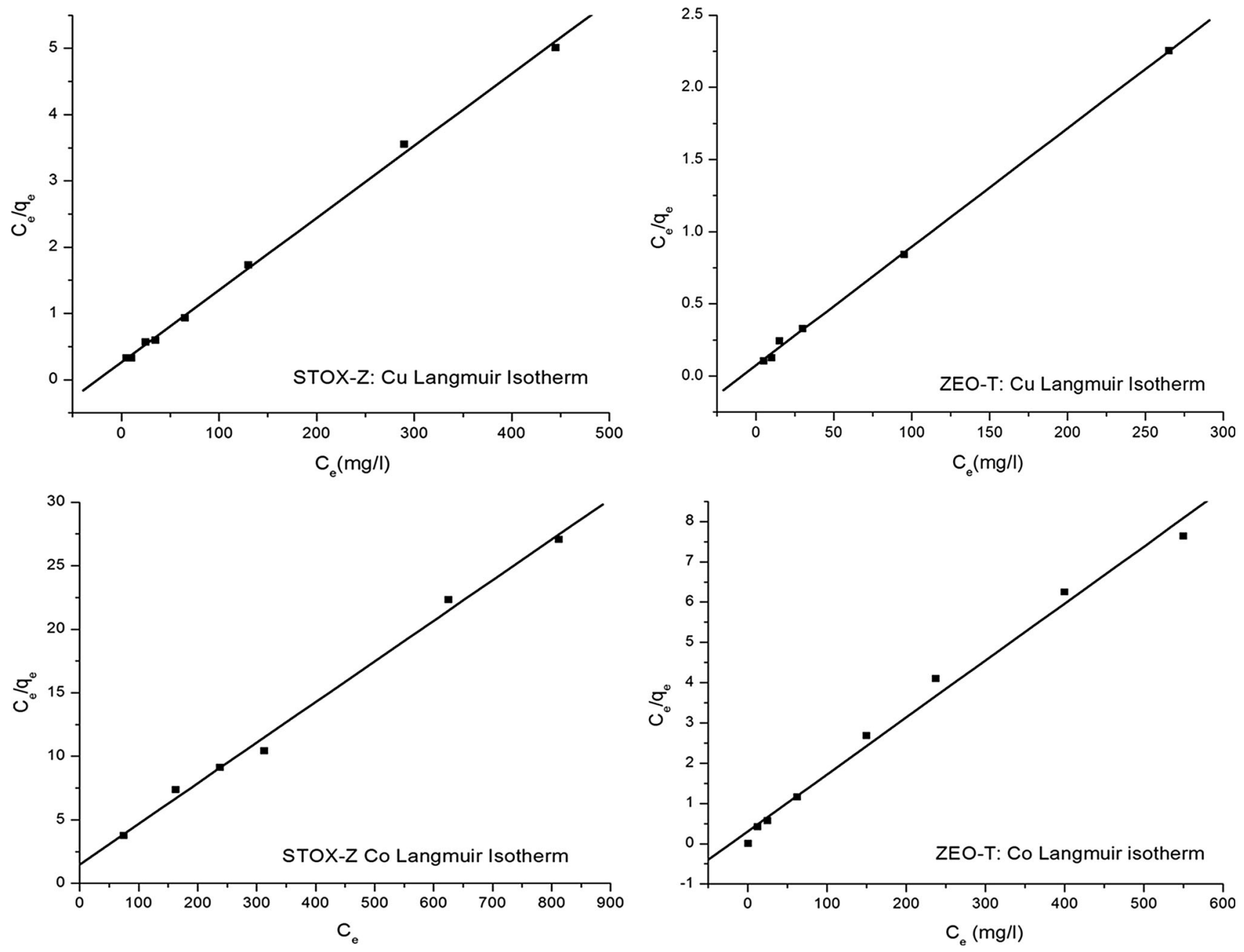

Fig. 5 Langmuir isotherms for $\mathrm{Cu}^{2+}$ and $\mathrm{Co}^{2+}$ adsorption on modified diatomaceous ceramic adsorbents

Freundlich adsorption isotherms using the well-known liquid isotherm equations. The linearized Langmuir isotherm is represented by Eq. (2):

$\frac{C_{\mathrm{e}}}{q_{\mathrm{e}}}=\frac{1}{b q_{\max }}+\frac{C_{\mathrm{e}}}{q_{\max }}$.

The linear plots of specific adsorption $\left(C_{\mathrm{e}} / q_{\mathrm{e}}\right)$ against the equilibrium concentrations $\left(C_{\mathrm{e}}\right)$ are shown in Fig. 4 . It indicates that $\mathrm{Cu}^{2+}$ and $\mathrm{Co}^{2+}$ adsorptions on the diatomaceous ceramic adsorbent conveniently obey the Langmuir isotherm model. The constants $b$ and $q_{\max }$ relate to the energy of adsorption and maximum adsorption capacity, and their values are obtained from the interception and slope of the plots and are presented in Table 3. The Freundlich isotherm is introduced as an empirical model, where $q_{\mathrm{e}}$ represents the amount adsorbed 

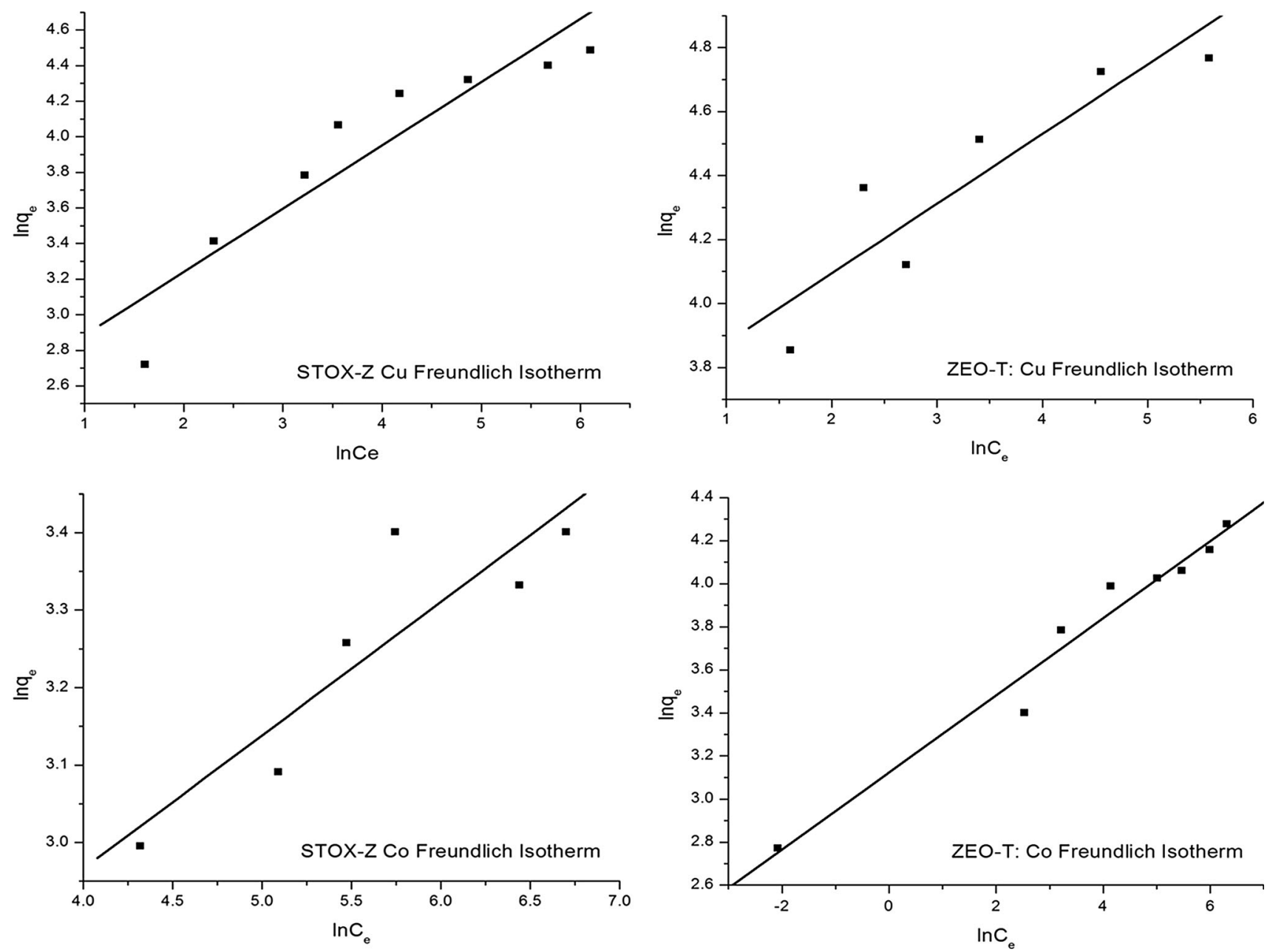

Fig. 6 Freundlich Isotherms for $\mathrm{Cu}^{2+}$ and $\mathrm{Co}^{2+}$ adsorption on modified diatomaceous ceramic adsorbents

per amount of adsorbent at the equilibrium $(\mathrm{mg} / \mathrm{g}), C_{\mathrm{e}}$ represents the equilibrium concentration $(\mathrm{mg} / \mathrm{l})$, and $K_{\mathrm{f}}$ and $n$ are parameters that depend on the adsorbate and adsorbent (Fig. 5). Considering the Freundlich equation below:

$q_{\mathrm{e}}=K_{\mathrm{f}} C_{\mathrm{e}}^{1 / n}$.

The equation can be linearized and the temperaturedependent constants $K_{\mathrm{f}}$ and $1 / n$ can be obtained by linear regression:

$\ln q_{\mathrm{e}}=\ln K_{\mathrm{f}}-\frac{1}{n} \ln C_{\mathrm{e}}$,

where $K_{\mathrm{f}}$ and $n$ are Freundlich constants which correspond to adsorption capacity and adsorption intensity, respectively. Freundlich equilibrium constants were determined from the plot of $\ln q_{\mathrm{e}}$ versus $\ln C_{\mathrm{e}}$ in Fig. 6 on the basis of the linear form of Freundlich equation. The $n$ value indicates the degree of nonlinearity between solution concentration and adsorption as follows: if $n=1$, then adsorption is linear; if $n<1$, then adsorption is a chemical process; if $n>1$, then adsorption is a physical process. The $n$ value obtained from Freundlich isotherm model for $\mathrm{Cu}^{2+}$ and $\mathrm{Co}^{2+}$ was found to be 2.813 and 5.801 for $\mathrm{Cu}$ (II) and Co (II), respectively, on adsorbent STOX-Z, as shown in Table 3. The situation $n>1$ is most common and may be due to a distribution of surface sites or any factor that causes a decrease in adsorbent-adsorbate interaction with increasing surface density (Reed and Matsumoto 1993) and the values of $n$ within the range of 1-10 represent good adsorption (McKay et al. 1980; Ozer and Pirincci 2006). In the present study, since $n$ lies between values 2 and 6 , it indicates a physical adsorption of metal ions onto diatomaceous ceramic adsorbent. In both cases, linear plots were obtained, though the degree of linearity of the Langmuir isotherm plots is higher than that of Freundlich isotherms. However, this reveals the applicability of these isotherms 
on the ongoing adsorption process. Complete Langmuir and Freundlich constants with corresponding correlation coefficients $(R)$, derived from the isotherm plots for the adsorption of cations on the adsorbents STOX-Z and ZEO$\mathrm{T}$, are shown in Table 3. To find the most appropriate model for the metal ions adsorption on aluminosilicates ceramic adsorbents, data were fitted to Langmuir and Freundlich isotherm models and the results indicated that Langmuir adsorption isotherm was the best model for the metal ions adsorption with $R$ of up to 0.99953 in the case of $\mathrm{Cu}$ (II) ion on ZEO-T. Langmuir adsorption isotherm parameters can be used to predict the affinity between the sorbate and sorbent using a dimensionless constant called separation factor or equilibrium parameter $\left(R_{\mathrm{L}}\right)$, which is expressed by the following relationship (Hall et al. 1966; Malik 2004):

$R_{\mathrm{L}}=\frac{1}{\left(1+b C_{\mathrm{i}}\right)}$,

where $b$ is the Langmuir constant and $C_{\mathrm{i}}$ is the initial concentration. The value of $R_{\mathrm{L}}$ indicated the type of Langmuir isotherm to be irreversible $\left(R_{\mathrm{L}}=0\right)$, linear $\left(R_{\mathrm{L}}=1\right)$, unfavorable $\left(R_{\mathrm{L}}>1\right)$, or favorable $\left(0<R_{\mathrm{L}}<1\right)$ (McKay et al. 1980). The $R_{\mathrm{L}}$ values between 0 and 1 indicate favorable adsorption. The $R_{\mathrm{L}}$ value in the present investigation was found to be $0.009-0.319$, showing that the adsorption of the metal ion the modified materials is favorable.

\section{Conclusions}

Photocatalytic diatomaceous ceramic adsorbents were successfully prepared using $\mathrm{Ag}-\mathrm{TiO}_{2}$ nanoparticles and activated diatomaceous aluminosilicate minerals for photodegradation and removal of $\mathrm{Cu}$ (II) and Co (II) from relatively high concentration aqueous solutions $(100-1000 \mathrm{mg} / \mathrm{l})$. The results and the parameters obtained indicated conclusively that photocatalytically modified diatomaceous ceramic adsorbents are capable of removing $\mathrm{Cu}$ (II) and $\mathrm{Co}$ (II) ions from relatively high concentrated aqueous solutions. Nonetheless, thermally fused ZEO-T offered greater adsorption capacity for both cations. Moreover, it is presented that both Freundlich and Langmuir isotherms can be used to fit the data and estimate model parameters; however, the overall data are slightly better fitted by Langmuir isotherm for both cations. Considering its microstructural characteristics, obtainability and abundance, photocatalytic diatomaceous ceramic adsorbent is economically viable and environmentally friendly for use, especially in developing countries. It can also be effectively applied as a pretreatment antidote for high concentration toxic effluents.
Acknowledgements The support of Department of Physics and Centre for Energy Research and Development, Obafemi Awolowo University, Ile-Ife, Nigeria is gratefully appreciated.

Open Access This article is distributed under the terms of the Creative Commons Attribution 4.0 International License (http:// creativecommons.org/licenses/by/4.0/), which permits unrestricted use, distribution, and reproduction in any medium, provided you give appropriate credit to the original author(s) and the source, provide a link to the Creative Commons license, and indicate if changes were made.

\section{References}

Ajenifuja E, Ajao JA, Ajayi EOB (2016) Equilibrium adsorption isotherm studies of $\mathrm{Cu}$ (II) and $\mathrm{Co}$ (II) in high concentration aqueous solutions on $\mathrm{Ag}-\mathrm{TiO}_{2}$-modified kaolinite ceramic adsorbents. Appl Water Sci. doi:10.1007/s13201-016-0403-6

Apostoli P et al (2012) High doses of cobalt induce optic and auditory neuropathy. Exp Toxicol Pathol 6:719-727

Araya M et al (2005) Effect of chronic copper exposure during early life in rhesus monkeys. Am J Clin Nutr 81:1065-1071

Bhattacharyya KG, Gupta SS (2006) Kaolinite, montmorillonite, and their modified derivatives as adsorbents for removal of $\mathrm{Cu}(\mathrm{II})$ from aqueous solution. Sep Purif Technol 50(3):388-397

Bhattacharyya KG, Gupta SS (2008a) Adsorption of a few heavy metals on natural and modified kaolinite and montmorillonite: a review. Adv Colloid Interface Sci 140:114-131

Bhattacharyya KG, Gupta SS (2008b) Kaolinite and montmorillonite as adsorbents for $\mathrm{Fe}(\mathrm{III}), \mathrm{Co}(\mathrm{II})$ and $\mathrm{Ni}(\mathrm{II})$ in aqueous medium. Appl Clay Sci 41:1-9

Chermisinoff P, Ellerbusch F (1978) Carbon adsorption handbook. Ann Arbor Science, Ann Arbor

Choi J-W, Hong S-W, Kim D-J, Lee S-H (2012) Investigation of phosphate removal using sulphate-coated zeolite for ion exchange. Environ Technol 33(20):2329-2335

Danil de Namor AF et al (2012) Turning the volume down on heavy metals using tuned diatomite. A review of diatomite and modified diatomite for the extraction of heavy metals from water. J Hazard Mater 241-242:14-31

De Castro Dantas TN, Neto AAD, De A Moura MCP (2001) Removal of chromium from aqueous solutions by diatomite treated with microemulsion. Water Res 35(9):2219-2224

Desai V, Kaler SG (2008) Role of copper in human neurological disorders. Am J Clin Nutr 88:855S-858S

Gupta SS, Bhattacharyyab KG (2008) Immobilization of $\mathrm{Pb}(\mathrm{II})$, $\mathrm{Cd}(\mathrm{II})$ and $\mathrm{Ni}(\mathrm{II})$ ions on kaolinite and montmorillonite surfaces from aqueous medium. J Environ Manag 87:46-58

Hall KR, Eagleton LC, Acrivos A, Vermeulen T (1966) Pore- and solid-diffusion kinetics in fixed-bed adsorption under constantpattern conditions. Ind Eng Chem Fundam 5(2):212-223

Hameed BH, Din ATM, Ahmad AL (2007) Adsorption of methylene blue onto bamboo-based activated carbon: kinetics and equilibrium studies. J Hazard Mater 141(3):819-825

Han R et al (2006) Copper (II) and Lead (II) removal from aqueous solution in fixed-bed columns by manganese oxide coated zeolite. J Hazard Mater 137:934-942

Han R et al (2009) Characterization and properties of ion oxidecoated zeolite as adsorbent for removal of copper (II) from solution in fixed bed column. Chem Eng J 149:123-131

Hanaor DAH, Sorrell CC (2014) Sand supported mixed-phase TiO2 photocatalysts for water decontamination applications. Adv Eng Mater 16(2):248-254 
Hanaor D, Michelazzi M, Leonelli C, Sorrell CC (2011) The effects of firing conditions on the properties of electrophoretically deposited titanium dioxide films on graphite substrates. J Eur Ceram Soc 31(15):2877-2885

Irani M, Amjadi M, Mousavian MA (2011) Comparative study of lead sorption onto natural perlite, dolomite and diatomite. Chem Eng J $178: 317-323$

Jeon CS et al (2009) Adsorption characteristics of As (V) on ironcoated zeolite. J Hazard Mater 163:804-808

Jiang M-Q, Jin X-Y, Lu X-Q, Chen Z-L (2010) Adsorption of Pb(II), $\mathrm{Cd}(\mathrm{II}), \mathrm{Ni}(\mathrm{II})$ and $\mathrm{Cu}(\mathrm{II})$ onto natural kaolinite clay. Desalination 252:33-39

Johnson EP, Milne DB, Lykken GI (1992) Effects of age and sex on copper absorption, biological half-life, and status in humans. Am J Clin Nutr 56:917-925

Kamegawa T, Kido R, Yamahana D, Yamashita H (2013) Design of TiO2-zeolite composites with enhanced photocatalytic performances under irradiation of UV and visible light. Microporous Mesoporous Mater 165:142-147

Karaoğlu MH, Doğan M, Alkan M (2010) Kinetic analysis of reactive blue 221 adsorption on kaolinite. Desalination 256:154-165

Khan TA, Khan EA, Shahjahan (2015) Removal of basic dyes from aqueous solution by adsorption onto binary iron-manganese oxide coated kaolinite: non-linear isotherm and kinetics modeling. Appl Clay Sci 107:70-77

Kim JH, Gibb HJ, Howe PD, Wood M (2006) Cobalt and inorganic cobalt compounds. World Health Organ, Geneva

Knoerr R, Brendlé J, Lebeau B, Demais H (2013) Preparation of ferric oxide modified diatomite and its application in the remediation of As(III) species from solution. Microporous Mesoporous Mater 169:185-191

Kujawa $\mathbf{J}$ et al (2013) Membrane distillation properties of $\mathrm{TiO} 2$ ceramic membranes modified by perfluoroalkylsilanes. Desalination Water Treat 51(7-9):1352-1361

Lasek J, Yu Y-H, Wu JCS (2012) Water and temperature effects on photo-selective catalytic reduction of nitric oxide on Pd-loaded TiO2 photocatalyst. Environ Technol 33(18):2133-2141

Linghu W, Cui J (2014) Removal of heavy metal ions from aqueous solution by raw and modified diatomite. Appl Mech Mater 522-524:656-659

Lippens BC, De Boer JH (1965) Studies on pore systems in catalysts V. The t Method. J Catal 4:319-323

Liu J et al (2013) Remove of Heavy Metals $\left(\mathrm{Cu}^{2+}, \mathrm{Pb}^{2+}, \mathrm{Zn}^{2+}\right.$ and $\mathrm{Cd}^{2+}$ ) in water through modified diatomite. Chem Res Chin Univ 29(3):445-448

Malik PK (2004) Dye removal from wastewater using activated carbon developed from sawdust: adsorption equilibrium and kinetics. J Hazard Mater 113(1-3):81-88

McKay G, Otterburn MS, Sweeney AG (1980) The removal of colour from effluent using various adsorbents. III. Silica: rate processes. Water Res 14(1):15-20

Mendy A, Gasana J, Vieira E (2012) Urinary heavy metals and associated medical conditions in the US adult population. Int $\mathrm{J}$ Environ Health Res 22(2):10518

Mittal A, Kurup L (2006) Column operations for the removal and recovery of a hazardous dye 'acid red 27 ' from aqueous solutions, using waste materials bottom ash and deoiled soya. Ecol Environ Conserv Paper 12(2):181-186

Mittal A, Ahmad R, Hasan I (2015a) Biosorption of $\mathrm{Pb}^{2+}, \mathrm{Ni}^{2+}$ and $\mathrm{Cu}^{2+}$ ions from aqueous solutions by L-cystein-modified montmorillonite-immobilized alginate nanocomposite. Desalination Water Treat $1-18$
Mittal A et al (2015b) Fabrication of MWCNTs/ThO2 nanocomposite and its adsorption behavior for the removal of $\mathrm{Pb}$ (II) metal from aqueous medium. Desalination Water Treat 1-7

Moradi O, Mirza B, Norouzi M, Fakhri A (2012) Removal of Co(II), $\mathrm{Cu}$ (II) and $\mathrm{Pb}$ (II) ions by polymer based 2-hydroxyethyl methacrylate: thermodynamics and desorption studies. Iran $\mathbf{J}$ Environ Health Sci Eng 9(1):31

Naushad M, Mittal A, Rathore M, Gupta V (2014) Ion-exchange kinetic studies for $\mathrm{Cd}(\mathrm{II}), \mathrm{Co}(\mathrm{II}), \mathrm{Cu}(\mathrm{II})$, and $\mathrm{Pb}$ (II) metal ions over a composite cation exchanger. Desalination Water Treat $1-8$

Ozer A, Pirincci HB (2006) The adsorption of Cd(II) ions on sulphuric acid-treated wheat bran. J Hazard Mater 137(2):849-855

Pfeiffer CC (1997) Nutrition and mental illness: an orthomolecular approach to balancing body chemistry. Healing Arts Press, Rochester

Pookmanee P, Thippraphan P, Phanichphant S (2011) Removal of Heavy Metals from Aqueous Solution by Natural and Modified Diatomite. J Microsc Soc Thail 4(2):103-107

Reed BE, Matsumoto MR (1993) Modeling cadmium adsorption by activated carbon using the Langmuir and Freundlich isotherm expressions. Sep Sci Technol 28(13-14):2179-2195

Rio S, Patrick M (2012) Removal of metal ions from aqueous solution by adsorption onto low-cost biosorbent. Environ Technol 33(19):2211-2215

Şan O, Gören R, Özgür C (2009) Purification of diatomite powder by acid leaching for use in fabrication of porous ceramics. Int $\mathrm{J}$ Miner Process 93:6-10

Shawabkeh R (1998) Synthesis of novel activated carbon from pecan shells and application to the adsorption of methylene blue, copper, and strontium from aqueous solutions. s.n., Las Cruces

Sheng G, Hu J, Wang X (2008) Sorption properties of Th(IV) on the raw diatomite- effects of contact time, $\mathrm{pH}$, ionic strength and temperature. Appl Radiat Isot 66:1313-1320

Sheng G, Dong H, Li Y (2012) Characterization of diatomite and its application for the retention of radiocobalt: role of environmental parameters. J Environ Radioact 113(108e):115

Sprynskyy M, Kovalchuk I, Buszewski B (2010) The separation of uranium ions by natural and modified diatomite from aqueous solution. J Hazard Mater 181:700-707

Wu J, Yang YS, Lin J (2005) Advance tertiary treatment of municipal wastewater using raw and modified diatomite. J Hazard Mater 127(1-3):196-203

Wu P, Xie R, Imlay JA, Shang JK (2009) Visible-light-induced photocatalytic inactivation of bacteria by composite photocatalysts of palladium oxide and nitrogen-doped titanium oxide. Appl Catal B 88(3-4):576-581

Yang JK et al (2012) Photocatalytic removal of $\mathrm{Cr}(\mathrm{VI})$ with illuminated $\mathrm{TiO} 2$. Desalination and water treatment 46(1-3):375-380

Yusan S, Gok C, Erenturk S, Aytas S (2012) Adsorptive removal of thorium (IV) using calcined and flux calcined diatomite from Turkey: evaluation of equilibrium, kinetic and thermodynamic data. Appl Clay Sci 67-68:106-116

Zhu J et al (2012) Adsorption of $\mathrm{Pb} 2+$ ions on diatomite modified by polypropylene acetamide and barium chloride in aqueous solution. Afr J Agric Res 7(24):3614-3620

Zou W, Zhao L, Han R (2009) Removal of uranium (VI) by fixed-bed ion exchange column using natural zeolite coated with manganese oxide. Chinese J. Chem. Eng. 17(4):585-593 